Pak. j. sci. ind. res. Ser. B: biol. sci. 2019 62B(3) 159-163

\title{
Apoptotic Potency of Bawang Dayak(Elutherine americana) Bulb Extract as Inhibitor of BPH through Computational Studies
}

\author{
Hendra Sutapa ${ }^{a b *}$, Didik Huswo Utomo ${ }^{c, g}$, Mohammad Aris Widodod, \\ Basuki Bambang Purnomo ${ }^{\mathrm{e}}$ and Doddy Moesbadianto Soebadi ${ }^{\mathrm{f}}$ \\ ${ }^{a}$ Doctoral Program of Medical Science, Faculty of Medicine, Brawijaya University,Malang, East Java, Indonesia \\ ${ }^{b}$ Department of Surgery, Faculty of Medicine, Lambung Mangkurat University, \\ Banjarmasin, South Kalimantan, Indonesia \\ ${ }^{c}$ Department of Biology, Faculty of Mathematics and Natural Sciences, Brawijaya \\ University, Malang, East Java, Indonesia \\ ${ }^{\mathrm{d}}$ Department of Pharmacology, Faculty of Medicine, Brawijaya University, Malang, East Java, Indonesia \\ e Department of Urology, Faculty of Medicine, Brawijaya University, Malang, East Java, Indonesia \\ ${ }^{\mathrm{f}}$ Department of Urology, Faculty of Medicine, Airlangga University, Surabaya, East Java, Indonesia \\ ${ }^{g}$ Research and Education Center for Bioinformatics, Nusantara Institute of Science and Technology, \\ Malang, East Java, Indonesia
}

(received July 7, 2018; revised February 28, 2018; accepted March 12, 2018)

\begin{abstract}
Benign Prostatic Hyperplasia (BPH) is indicated by hyperproliferation of prostate epithelial and stromal cells. Bawang Dayak (Elutherine americana) is an Indonesian endemic plant which is used as herbal medicine for BPH. This study aimed to reveal the potency of Bawang Dayak bulbs extracts as an inhibitor agent of BPH cells. The research was conducted based on in silico approach. The 3D structure of active compound and protein target were studied and analyzed molecular interaction, calculated binding affinity, and pharmacophore, visualized biomolecules, and analyzed biological activity of each active compound. They are naphthalene, naphthoquinone, and anthraquinone. All active compounds have a higher binding affinity to $\mathrm{COX}-2$. It has the highest binding affinity value around $-8.7 \mathrm{Kcal} / \mathrm{mol}$. Anthraquinone has an ability as anti-inflammatory and apoptosis agonist, which blocks the COX-2 active site, so, the Bcl2 would be inactivated and apoptosis can occur immediately.
\end{abstract}

Keywords: benign prostatic hyperplasia, Elutherine anericana, anti-inflammatory, apoptotic poteney

\section{Introduction}

Benign prostatic hyperplasia (BPH) is prostate gland enlargement which is not categorized as cancer. Severe symptoms of BPH occur in men after the age of 60 80 years. BPH has high prevalence in the world (Dhingra et al., 2011). Epidemiological evidence has shown that age, genetics, lifestyle, and inflammation are the risk factors of BPH. The intraprostatic inflammation has also been strongly related to its development and progression which is caused by the inflammatory cytokine Interleukin-17 (IL-17) released by T cells. Based on the recent study, IL-17 is not expressed in the normal prostate (Ishiguro and Kawahara, 2014; De Nunzio et al., 2011). The secretion of IL-17 will increase the Cyclooxygenase-2 (COX-2) expression in the BPH epithelial cells (De Nunzio et al., 2011). COX-2 expression is associated with increasing cell proliferation

*Author for correspondence; E-mail:

capa.journal23@gmail.com and anti-apoptotic Bcl-2 level ( Li et al., 2017; Ishiguro and Kawahara, 2014). Bcl-2 overexpression will lead to the decrease of pro-apoptotic protein Bax and imbalance between cell proliferation and apoptosis (Zheng et al., 2013; Roehrborn, 2012). Additionally, the COX-2 activity has already been detected in all inflammatory cells within the epithelium and intestinal spaces of human prostate tissues (Chughtai et al., 2011). Besides IL-17, expression of COX-2 also induced by several inducers such as hormone (FSH, LH), proinflammatory cytokine (TNF- $\propto$, INF- $\gamma$, LPS), growth factor (EGF, PDGF, FGF) and oncogene (v-Src, v-Ras). The regulation of COX-2 is belonging to the Nuclear Factor-kB (NF-kB) pathway. LPS will induce TLR-4 receptor activation, whereas IL- $1 \beta$ will activate the IL1. The activation of TLR-4 and IL-1 $\beta$ will induce the adaptor molecule, MyD88. Then, it will induce IRAK and interact with TRAF6 to activate the NF-kB inducing kinase (NIK). Moreover, NIK will activate IkB kinase 
(IKK) which causes a phosphorylation of inhibition of NF-kB (IkB) and NF-kB activation.

Moreover, the prostatic inflammation leads to the free radicals generation, like nitric oxide (NO). These free radicals may also lead the conversion of COX enzymes into prostaglandin which is involved in the prostate cell proliferation. NO and COX activity involves the association between prostate inflammation and growth. Inflammatory cells in prostate are capable to induce NO synthase (iNOS) and activating reactive nitrogens that can damage cells. iNOS expression in human prostate tissues has been characterized in the BPH epithelial cells (Chughtai et al., 2011; Wang et al., 2004).

Bawang Dayak (Elutherine americana Merr) which belongs to Iridaceae family is an endemic plant in the Kalimantan, Indonesia which is widely used in traditional medicines (Kuntorini and Nugroho, 2010). Moreover, Bawang Dayak bulb was identified to contain 34 compounds divided into three big group compounds i.e. naphthalene, naphthoquinone, and anthraquinone. (Insanu et al. 2014). These compounds, according to another research on different plant, showed an inhibitory effect on COX-2 (Kaur et al., 2009; Shin et al., 2006; Kongkathip et al., 2005; Oku and Ishiguro, 2002). It is strongly believed that it cure the BPH (Indrawati and Razimin, 2013 ) but the molecular mechanism is still unclear. Therefore, this study was aimed to reveal the potency of Bawang Dayak (Elutherine americana) bulb extract as inhibitor agent towards Benign Prostatic Hyperplasia (BPH) through computational study.

\section{Materials and Methods}

Data retrieval. The 3D structure of naphthalene (CID: 931), naphthoquinone (CID: 8530) and anthraquinone (CID: 6780) were collected from PubChem (www.pubchem.ncbi.nlm.nih.gov). Moreover, they were minimized by Open Babel to get the favorable structure with minimum energy, while the 3D structure of protein target of COX-2 (PDB ID: 1VOX) and iNOS (PDB ID $4 \mathrm{NOS}$ ) were collected from Protein Data Bank (PDB) (www.rscb.org/pdb/home.do). Furthermore, the 3D structure of IkB kinase was obtained from homology modeling using Swiss-Model. Then, each of these protein target structures were prepared by Vega ZZ to remove the native ligands and water molecule from protein complex. It was important for docking preparation (Fig. 1).
Molecular docking and interaction. Each active compound of Elutherine americana Merr (naphthalene, naphthoquinone, and anthraquinone) was docked to the protein target active site. Docking process was carried out using autodock vina in Pyrx 0.8 (Latha and Saddala, 2017; Trott and Olson, 2010). This process was aimed

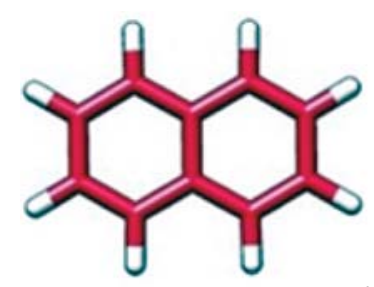

Napthalene

(a)

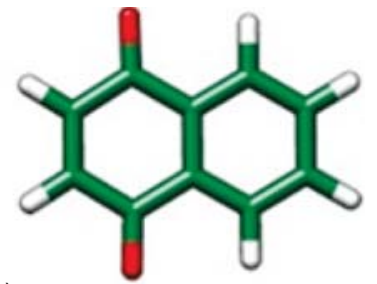

Napthoquinone

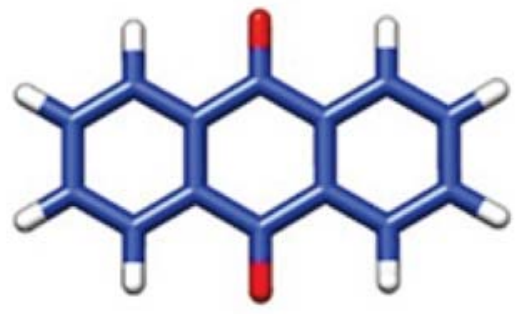

Anthraquinone

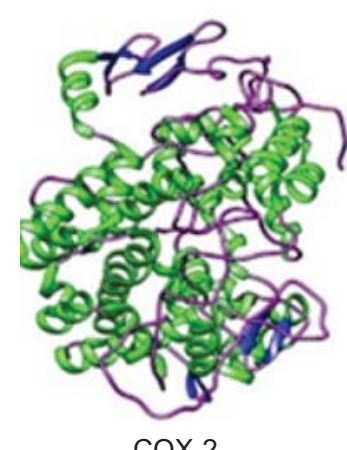

COX-2

(b)
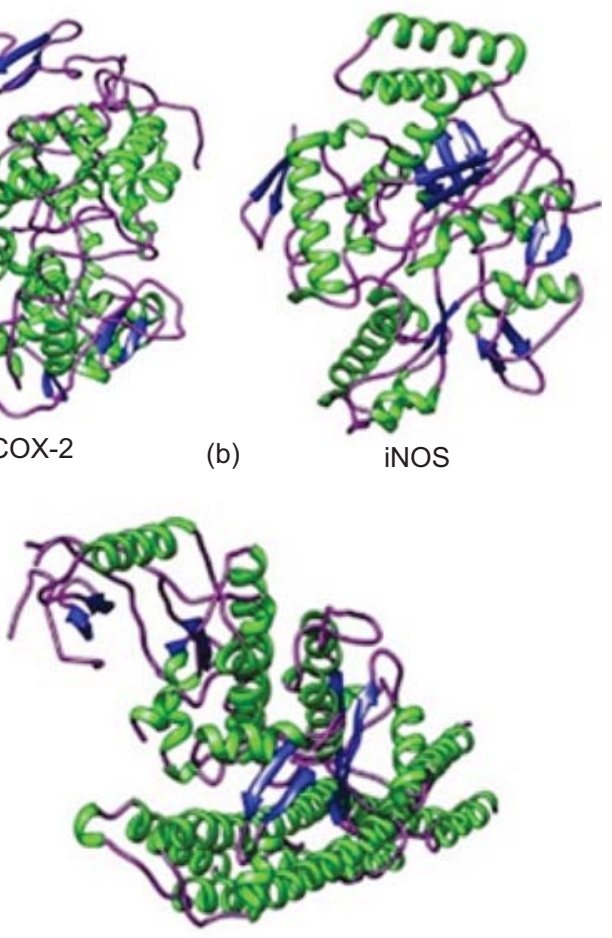

IkB Kinase

Fig. 1. The 3D structure of active compound of (a) Elutherine americana and (b) protein target 
to identify the inhibitory potency and to calculate the binding affinity between ligand and protein. The molecular interactions were analyzed by LigandScout (Wolber and Langer, 2005). It was aimed to identify the amino acids involved in the interaction with the ligands. Active compound and protein target were visualized using CHIMERA 1.8.1 to generate the representative visualization (Pettersen et al., 2004).

Biological activity prediction. The biological activity of naphthalene, naphthoquinone, and anthraquinone was analyzed using PASS online server based on structure activity relationship (SAR) approach. It would be resulting $\mathrm{Pa}$ (Probability activity) and Pi (Probability inactivity) values ranging from 0 to 1 . Values $\mathrm{Pa}>\mathrm{Pi}$ were considered to be more accurate prediction (Goel et al., 2014).

\section{Results and Discussion}

Molecular docking is widely used to identify and predict a new ligand for protein target in the specific site. Generally, the potential of an active compound (ligand) is determined by binding affinity value in docking process. Table 1 shows that each active compound of Bawang Dayak is strongly bound to the protein target. Moreover, all active compounds have shown the strongest binding affinity for COX-2. They can bind to iNOS or IkB kinase but with the lower affinity. COX2 is the most potential target for the active compound from Bawang Dayak with the highest affinity -8.7 $\mathrm{Kcal} / \mathrm{mol}$

TYR371 is a cite active of COX-2 which has been involved in the cyclooxygenase activity. The molecular interaction analysis showed that each active compound interacts with TYR371 (Fig. 2). Anthraquinone interacts

Table 1. Result of molecular docking between active compound of Bawang Dayak and protein target

\begin{tabular}{lll}
\hline \hline $\begin{array}{l}\text { Active compound } \\
\text { (Ligand) }\end{array}$ & Protein target & $\begin{array}{l}\text { Binding affinity } \\
(\mathrm{Kcal} / \mathrm{mol})\end{array}$ \\
\hline Naphthalene & & -7.0 \\
Naphthoquinone & COX-2 & -7.3 \\
Anthraquinone & & -8.7 \\
Naphthalene & & -5.8 \\
Naphthoquinone & iNOS & -6.8 \\
Anthraquinone & & -7.2 \\
Naphthalene & & -6.9 \\
Naphthoquinone & IkB kinase & -6.6 \\
Anthraquinone & & -7.6 \\
\hline \hline
\end{tabular}

to TYR371 through hydrogen bond, while naphthalene and naphthoquinone interact to TYR371 through a hydrophobic bond. It means that anthraquinone has stronger binding to COX-2 and supported by the highest affinity value. It may have a potential effect on the inhibition mechanism.

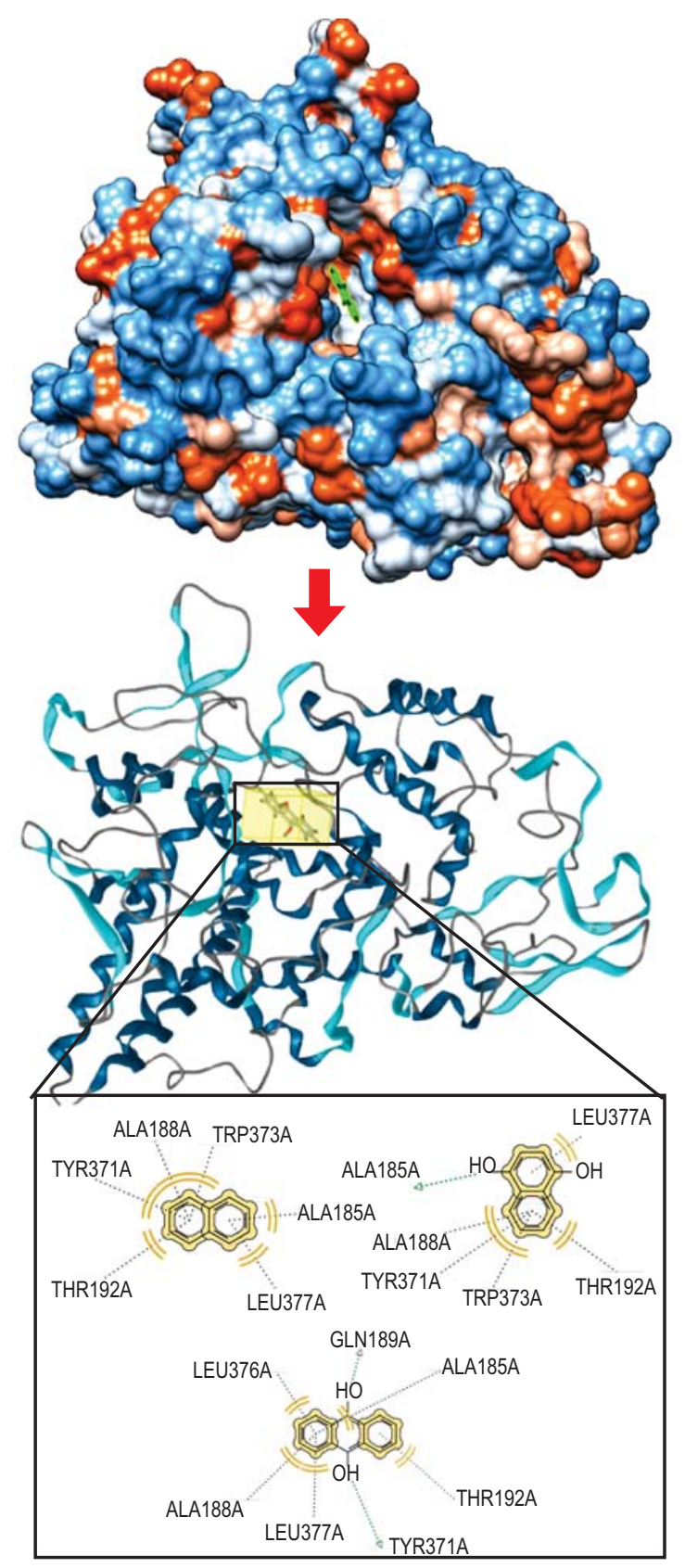

Fig. 2. Molecular interaction of naphthalene, naphthoquinone, and anthraquinone with active site of $\mathrm{COX}-2$ 
Analysis of the biological activity showed that naphthoquinone is the most potential; anti-inflammatory and apoptosis agonist. This compound has $\mathrm{Pa}$ value in the anti-inflammatory activity around 0.4 and Pa value in the apoptosis agonist activity around 0.64 , while anthraquinone has also showed high $\mathrm{Pa}$ value thus potential as anti-inflammatory and apoptosis agonist with the value 0.41 and 0.583 , respectively (Fig. 3). Threshold of $\mathrm{Pa}$ value is 0.3 with higher Pa value means higher accuaracy of prediction (Benchabane et al., 2009). Anthraquinone is the most potentially active compound for BPH therapy because it has the strongest binding affinity to COX-2 and can act as apoptosis agonist and anti-inflammatory agent.

Anthraquinone and naphthoquinone are involved in inhibition mechanism in COX-2 as anti-inflammatory and apoptosis agonist. Each of them is bound to the COX-2 specific active site. COX-2 will be inactivated by inhibiting the active site, so Bcl-2 is inactive and pro-apoptotic protein (Bax, Bid) would be increased and take a role in apoptosis process ( Fig. 4).

It is concluded that active compound from Bawang Dayak (Elutherine americana Merr) has higher affinity to COX-2 than iNOS and IkB kinase as a target protein. Anthraquinone has a biological activity as antiinflammatory and apoptosis agonist. It blocks COX-2

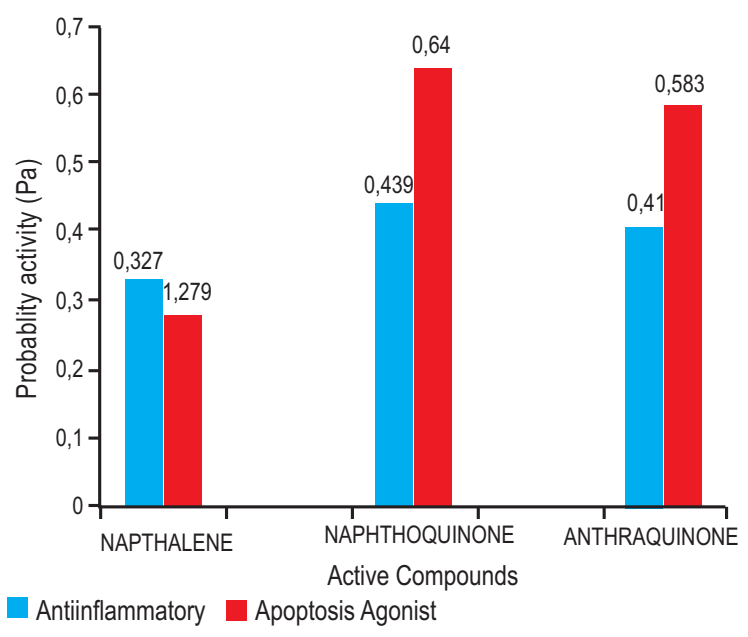

Fig. 3. Anti-inflammatory and apoptosis agonist activity of active compound in Bawang Dayak bulbs extract

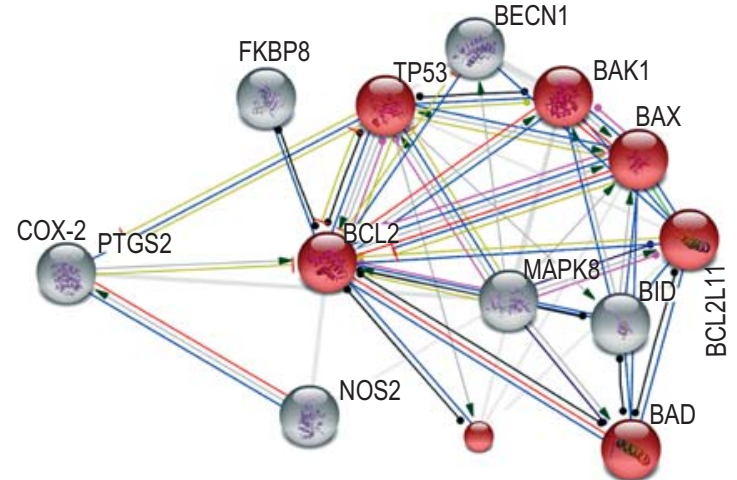

Fig. 4. Protein that has role in apoptosis mechanism (red) interact each other with COX-2 and Bcl-2

active site, so that, the Bcl-2 would be inactivated and apoptosis can occur immediately.

\section{Acknowledgement}

The authors would like to thank Bioinformatics Laboratory, Biology Department, Brawijaya University, Indonesia for facilitating this research.

Conflict of Interest. The authors declare no conflict of interest

\section{References}

Benchabane, Y., Di Giorgio, C., Boyer, G., Sabatier, A.S., Allegro, D., Peyrot, V., De Meo, M. 2009. Photo-inducible cytotoxic and clastogenic activities of 3,6-di-substituted acridines obtained by acylation of proflavine. European Journal of Medicinal Chemistry, 44: 2459-2467.

Chughtai, B., Lee, R., Te, A., Kaplan, S. 2011. Role of inflammation in benign prostatic hyperplasia. Reviews in Urology, 13: 147-150.

De Nunzio, C., Kramer, G., Marberger, M., Montironi, R., Nelson, W., Schröder, F., Sciarra, A., Tubaro, A. 2011. The controversial relationship between benign prostatic hyperplasia and prostate cancer: the role of inflammation. European Urology, 60: 106-117.

Dhingra, N., Bhagwat, D. 2011. Benign prostatic hyperplasia: An overview of existing treatment. Indian Journal of Pharmacology, 43: 6-12.

Goel, R.K., Singh, D., Lagunin, A., Poroikov, V. 2011. PASS-assisted exploration of new therapeutic 
potential of natural products. Medicinal Chemistry Research, 20: 1509-1514.

Indrawati, N.L., Razimin. 2013. Bawang Dayak Si Umbi Ajaib Penakluk Aneka Penyakit, 130 pp., PT AgroMedia Pustaka, Jakarta, Indonesia.

Insanu, M., Kusmardiyani, S., Hartati, R. 2014. Recent studies on phytochemicals and pharmacological effects of Eleutherine americana Merr. Procedia Chemistry, 13: 221-228.

Ishiguro, H., Kawahara, T. 2014. Nonsteroidal antiinflammatory drugs and prostatic diseases. BioMed Research International, 2014: 1-6.

Kaur, P., Kaur, S., Kumar, S., Singh, P. 2009. Rubia cordifolia L. and Glycyrrhiza glabra L. medicinal plants as potential source of COX-2 inhibitors. American Journal of Biomedical Sciences, 2: 108120.

Kongkathip, B., Sangma, C., Kirtikara, K., Luangkamin, S., Hasitapan, K., Jongkon, N., Hannongbua, S., Kongkathip, N. 2005. Inhibitory effect of 2substituted-1-naphthol derivatives on cyclooxygenase I and II. Bioorganic \& Medicinal Chemistry, 13: 2167-2175.

Kuntorini, E.M., Nugroho, L.H. 2010. Structural development and bioactive content of red bulb plant (Eleutherine americana); a traditional medicine for local Kalimantan people. Biodiversitas, 11: 102-106.

Latha, M.S., Saddala, M.S. 2017. Molecular docking based screening of a simulated HIF-1 protein model for potential inhibitors. Bioinformation, 13: 388-393.

Li, W., Cao, Y., Xu, J., Wang, Y., Li, W., Wang, Q., Hu, Z., Hao, Y., Hu, L., Sun, Y., Xu, G., Ao, G. 2017. YAP transcriptionally regulates COX-2 expression and GCCSysm-4 (G-4), a dual YAP/COX-2 inhibitor, overcomes drug resistance in colorectal cancer. Journal of Experimental \& Clinical Cancer Research, 36: 144.
Oku, H., Ishiguro, K. 2002. Cyclooxygenase-2 inhibitory 1,4-naphthoquinones from Impatiens balsamina L. Biological and Pharmaceutical Bulletin, 25: 658-660.

Pettersen, E.F., Goddard, T.D., Huang, C.C., Couch, G.S., Greenblatt, D.M., Meng, E.C., Ferrin, T.E. 2004. UCSF Chimera-a visualization system for exploratory research and analysis. Journal of Computational Chemistry, 25: 1605-1612.

Roehrborn, C.G. 2012. Benign Prostatic Hyperplasia Etiology, Pathophysiology, Epidemiology, and Natural History of Prostatic Hyperplasia. In: Campbell-Walsh Urology, 2556-2596 pp., $10^{\text {th }}$ edition, Saunders. Philadelphia, USA.

Shin, J.C., Moon, J.Y., Park, W.H. 2006. Inhibitory effect of Panax notoginseng and emodin on LPSinduced iNOS, COX-2 and prostaglandin E2. Korean Journal of Oriental Physiology \& Pathology, 20: 724-729.

Trott, O., Olson, A.J. 2010. AutoDock Vina: improving the speed and accuracy of docking with a new scoring function, efficient optimization and multithreading. Journal of Computational Chemistry, 31: 455-461.

Wang, W., Bergh, A., Damber, J.E. 2004. Chronic inflammation in benign prostate hyperplasia is associated with focal upregulation of cyclooxygenase-2, Bcl-2 and cell proliferation in the glandular epithelium. Prostate, 61: 60-72.

Wolber, G., Langer, T. 2005. LigandScout: 3-D pharmacophores derived from protein-bound ligands and their use as virtual screening filters. Journal of Chemical Information and Modeling, 45: 160-169.

www.rscb.org/pdb/home.do

Zheng, H., Xu, W., Lin, J., Peng, J., Hong, Z. 2013. Qianliening capsule treats benign prostatic hyperplasia via induction of prostatic cell apoptosis. Molecular Medicine Reports, 7: 848-854. 